História e Perspectivas, Uberlândia (57): 129-148, jul./dez. 2017

http://dx.doi.org/10.14393/HeP-v30n57-2017-5

\title{
TEMPO LIVRE E LAZER DOS TRABALHADORES NA MANCHESTER MINEIRA: REFLEXÕES ACERCA DOS RELATOS NOS PROCESSOS CRIME DE HOMICÍDIO (1900-1924)*
}

\author{
Cleber Augusto Gonçalves Dias** \\ Marina Fernandes Braga Nakayama***
}

RESUMO: Este trabalho apresenta algumas reflexões a respeito do tempo livre e do lazer dos trabalhadores em Juiz de Fora, uma cidade na Zona da Mata mineira, que se destacou nas primeiras décadas do século $X X$ devido ao incremento e diversidade das suas indústrias, comércio e serviços. Para tanto, utilizamos os processos crime de homicídio produzidos durante o período de 1900 a 1924, que se localizam no Arquivo Municipal de Juiz de Fora, procurando observar as práticas de lazer e a utilização dos espaços urbanos da cidade, com o objetivo de refletir sobre as práticas dos trabalhadores e os espaços de sociabilidade durante o tempo livre e lazer dos trabalhadores.

* Este artigo é a versão atualizada do trabalho apresentado no XXVIII Simpósio Nacional de História, de 2015, realizado em Florianópolis-SC. O trabalho, intitulado "Tempo Livre e lazer dos trabalhadores em Juiz de Fora/MG possibilidades através dos processos crime de homicídio (1900-1924)", consistia no resultado preliminar da pesquisa de doutorado em andamento.

** Doutor em Educação Física pela Unicamp e Mestre em História Comparada pela UFRJ. Coordenador do grupo de pesquisa em História do Lazer (HISLA) na EEFFTO/UFMG. Coordenador do Programa de Pós-Graduação Interdisciplinar em Estudos do Lazer da UFMG (2015/2016).

*** Doutoranda e bolsista CAPES-DS no Programa de Pós-Graduação Interdisciplinar em Estudos do Lazer da UFMG (2012-2016), linha de pesquisa "Lazer, história e memória". Mestre em Educação pela UFPR. Professora convidada no curso de Pós-Graduação Lato Sensu "Ensino de Educação Física para a Educação Básica" do Colégio de Aplicação João XXIII da Universidade Federal de Juiz de Fora (2015/2016), atuando na disciplina "Educação Física e Educação Física Escolar: Aportes Históricos, Sócio -Filosóficos e Epistemológicos". 
PALAVRAS-CHAVE: Lazer. Tempo livre. Processos crime.

ABSTRACT: This paper presents some reflections on the free time and the workers' leisure in Juiz de Fora, a city in Minas Gerais Forest Zone, which stood out in the first decades of the twentieth century due to the increase and diversity of its industries, trade and services. Therefore, we use the processes homicide crime that are in Juiz de Fora Municipal Archives during the period 1900-1924, seeking to observe the leisure practices and the use of urban spaces of the city, in order to reflect on the practical workers and spaces of sociability during free time and leisure of workers.

KEYWORDS: Laisure. Time free. Processes crime.

\section{Juiz de Fora: a Manchester Mineira}

Juiz de Fora é uma cidade do sudeste de Minas Gerais, localizada na Zona da Mata, entre a Serra da Mantiqueira e a Serra do Mar. No início do século $X X$, seguindo os passos de outras cidades do Brasil, tais como Rio de Janeiro (CHALHOUB, 1996, 2001), São Paulo (SEVCENKO, 1992, 1998, 1999) e Belo Horizonte (VEIGA, 2002; VAGO, 2002), a localidade vivenciava um processo de modernização e de reformas sanitárias, urbanísticas, educacionais, entre outras.

Para a historiadora Maraliz Christo (1994), entre meados do século XIX e o início do século XX, Juiz de Fora não foi herdeira da cultura colonial mineira. A cidade contava com um fator expressivo, a produção cafeeira, já que as terras da Zona da Mata mineira não eram propícias à extração de minerais, tal como as cidades da região central do estado.

Já em meados do século XIX, os primeiros traços de progresso podiam ser observados na localidade. Exemplos disso são a abertura da estrada de rodagem União e Indústria - a qual ligava a cidade à Capital Federal -, as comunicações 
ferroviárias e, ainda, a instalação da primeira usina hidrelétrica da América Latina - a Usina de Marmelos, que permitiu uma nova configuração do Rio Paraibuna, sendo inaugurada em 1889. Esses traços de desenvolvimento, que permaneceram ainda ativos durante o século $X X$, foram responsáveis pelo escoamento da produção cafeeira durante o século XIX e pelo escoamento de diversas mercadorias, como os artigos têxteis, alimentos e bebidas em Juiz de Fora e região (CHRISTO, 1994, p. 11).

Christo (1994, p. 10) ainda identifica uma singular diferença na formação urbana de Juiz de Fora em relação à de outras cidades barrocas de Minas Gerais, uma vez que essa estaria "normatizada pelos apitos das fábricas de estilo neoclássico e o bater dos tamancos de seus operários de ambos os sexos e diversas nacionalidades". Pode-se dizer que os libertos e os estrangeiros teriam presença marcante como mão de obra na cidade e região.

Contínuas transformações na paisagem da cidade mineira aconteceram, tais como obras de retificação do Rio Paraibuna, embelezamento da região central, com reforma de ruas, criação de praças, criação do matadouro, regulamentação das casas e de animais domésticos, tentativas de solucionar problemas relacionados a epidemias, entre outros, como nos apontam as Resoluções da Câmara Municipal de Juiz de Fora nas primeiras décadas do século XX. Exemplo disso foi a Resolução da Câmara $n^{\circ} 706$, que estabeleceu a proibição da abertura de avenidas para operários ou vielas que ficassem localizadas no centro da cidade. Ela também determinava a desapropriação e a demolição de imóveis que ficassem em avenidas abertas bem no meio dos quarteirões centrais, formando pequenas vilas na cidade (CÂMARA MUNICIPAL DE JUIZ DE FORA, 1917). Podese perceber uma preocupação com o uso e com a apropriação do centro da cidade, como aconteceu nas primeiras décadas do século XX em cidades como Rio de Janeiro, São Paulo, Belo Horizonte.

Ao mesmo tempo em que olhares se debruçavam sobre a cidade, entendendo-a como moderna, bela e próspera, as páginas 
do Jornal O Pharol, em 1907, destacavam más impressões: "conhecemos Juiz de Fora há anos, sempre atrasada e gozando de fama de um péssimo clima, o que lhe emprestavam as epidemias aqui ocorridas" (O PHAROL, 17 out. 1907); o que demonstrava a existência de contradições no processo de modernização da cidade nas primeiras décadas do século XX, bem como a intenção de organizar a localidade, dividindo seus espaços e determinando como seriam utilizados e ocupados.

Com uma população que, no ano de 1890 , atingiu 55.185 habitantes, e que, em 1920, chegou ao número de 118.166, incluindo pessoas do meio urbano e rural (GIROLETTI, 1988), a cidade de Juiz de Fora se expandiu significativamente em trinta anos. Além disso, a composição de seus habitantes foi alterada, tendo os libertos e os imigrantes como seus componentes. No caso dos imigrantes, várias nacionalidades podiam ser encontradas, incluindo os italianos, os portugueses, os espanhóis, os franceses, os norte-americanos, os árabes, entre outros em menor expressão quantitativa (OLIVEIRA, 1966).

Além do aspecto populacional, outra transformação socioeconômica que ocorreu, na época, como causa e consequência da redefinição da cidade, foi o aumento de casas comerciais, de oficinas e de fábricas. Em seu trabalho Industrialização de Juiz de Fora, publicado em 1988, Domingos Giroletti analisa como a cidade se tornou referência econômica para a Zona da Mata mineira frente ao desenvolvimento das indústrias nela estabelecidas. Para o autor, a cidade, até a década de 1930, transitou de uma grande produção cafeeira para um intenso processo de industrialização, o que exigiu sua reorganização em vários setores da economia para atender às novas demandas.

Segundo Giroletti (1988, p. 113-114), a participação da mão de obra de imigrantes europeus - que também se tornaram, em grande parte, pequenos empreendedores -, associada a empresários locais que fundaram as indústrias e possibilitaram o investimento em outros setores, como o de comércio e o de serviços, foram significativas para o alargamento e para o incremento da economia na cidade. 
No Almanach ${ }^{1}$ de Juiz de Fora, publicado em 1917, há um número significativo de anúncios de casas comerciais e de indústrias dos mais variados setores. Identificamos propagandas de tipografias, fábricas de balas e guloseimas, fábricas de tecidos e malhas, laboratórios químicos e industriais, fábricas de móveis, cervejarias, fábricas de máquinas, construtoras e fábricas de mantimentos (ALMANACH, 1917).

Também eram constantes as publicações de anúncios referentes a serviços diversos nos jornais que circulavam na cidade. Essa diversidade de mercado levou-nos à compreensão de por que a cidade se tornou referência para as demais em seu entorno. Além disso, era necessária a inserção de trabalhadores nas casas comerciais e nas fábricas, o que fazia com que a mão de obra da cidade se constituísse justamente para suprir as novas demandas. Assim, deixava-se para trás a produção cafeeira, que já não mais se constituía como o elemento central da economia da região.

Juiz de Fora apresentava-se como uma cidade com características próprias às cidades que se industrializavam e que se desenvolviam no início do Novecentos. Dentre essas características, podemos destacar que, durante as três primeiras décadas do século $X X$, foi de suma importância a atividade industrial, com o estabelecimento de vários tipos de produção, destacando-se a indústria têxtil.

A fim de corroborarmos essa ideia, disponibilizamos um anúncio datado de 1909, da Fábrica São Roque, localizada em Juiz de Fora. É interessante observar nele a variedade de artigos produzidos em uma mesma fábrica e a grande quantidade de máquinas a vapor necessárias para o seu funcionamento. Notase que o funcionamento dessa fábrica era dividido por seções, indicando sua pluralidade e ainda a possibilidade de abastecer os

1 Os Almanachs eram catálogos de propagandas e serviços encontrados na cidade, e, também, um meio de comerciantes e autônomos das cidades vizinhas realizarem seus anúncios. Ofereciam, além disso, orientações sobre horários de trens e momentos de leitura, através da publicação de poesias, crônicas e estórias. 
comerciantes da região de maneira atacadista, já que ela possuía estoque de produtos. Também é relevante destacar o número significativo de 220 operários na primeira década do Novecentos.

Figura 1: Anúncio da Fábrica São Roque

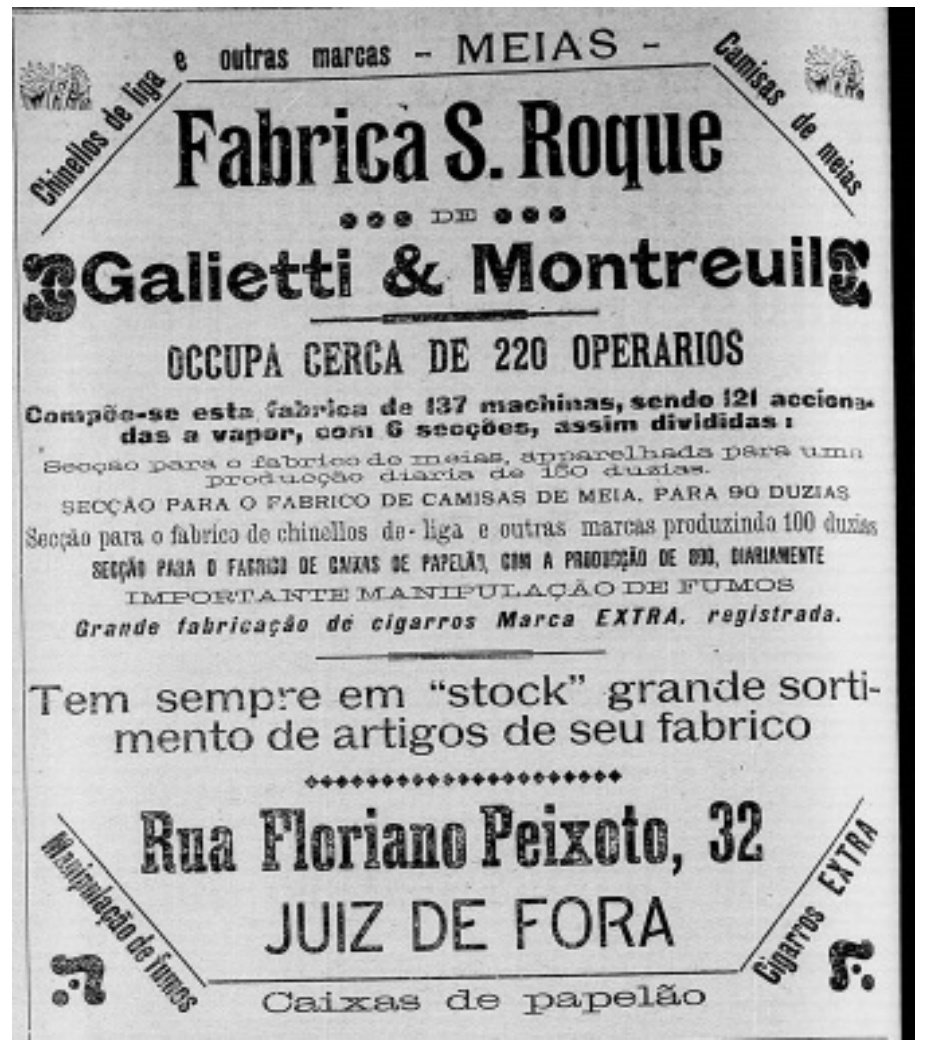

Fonte: Jornal O Pharol, Juiz de Fora, 11 set. 1909.

É por esses fatores e, especialmente, por causa do processo de industrialização, que Juiz de Fora foi identificada, nas últimas décadas do século XIX até o início do século XX, por Manchester Mineira. Esse epíteto ilustrava bem a condição da cidade mineira, que era comparada à cidade industrial de Manchester, localizada na Inglaterra. 
A partir desse conjunto de características, refletimos e levantamos algumas questões. Primeiramente, como, nessa cidade, tão ligada ao progresso, era utilizado o tempo livre dos trabalhadores ${ }^{2}$ ? Que atividades os trabalhadores realizavam durante o tempo do não trabalho?

Assim, ficamos nos questionando quais fontes de pesquisa permitiriam que um outro olhar, que não fosse ligado às classes mais abastadas, viesse à tona. Foi quando nos deparamos com o trabalho de Sidney Chalhoub (1994), que se orientou em identificar o cotidiano e a cultura dos trabalhadores no Rio de Janeiro por meio dos processos crime. Nesse caminho, também nos deparamos com o trabalho de Deivy Carneiro (2008), que estudou as injúrias por meio dos processos crime. Nesse viés, decidimos procurar, nas páginas dos processos de homicídio, registros que possibilitassem um olhar acerca do tempo livre e do lazer do trabalhador nessa cidade mineira.

\section{Os processos crime como fonte de pesquisa}

Os processos crime pesquisados para este estudo encontram-se sob guarda do Arquivo Histórico de Juiz de Fora, órgão da Prefeitura Municipal desta cidade, no Fundo Criminal do Fórum Benjamin Colucci. Esta documentação foi recolhida em 1996 em condições precárias, infestados por poeira, insetos, úmidos e até mesmo deteriorados. Após um trabalho de higienização, eles puderam ser organizados, levando-se em conta o período em que foram produzidos (se período do Império ou da República), e, conforme o delito cometido, foram criadas séries

2 Optamos por utilizar o termo "trabalhadores" aproximando-nos de Eric Hobsbawn (1987) que utiliza o termo trabalhadores de forma genérica, sem aplica-lo a uma tipologia específica de ocupação. No entanto optamos por equivaler trabalhador e operário, considerando a necessidade e a importância de se pesquisar as tradições e a formação desse tipo de trabalhador quando pensamos em Juiz de Fora, especialmente devido ao seu destaque fabril e industrial nas primeiras décadas do século XX. 
para sistematizá-los, nas quais os processos ficaram alocados em ordem cronológica de acordo com a data da notícia do crime.

A série por nós elencada foi a que englobava os processos crime de homicídio, inseridos na categoria de crimes contra a segurança da pessoa e da vida, referente ao período da República, entre os anos de 1891 e 1942.

No entanto, para este trabalho analisamos os processos abertos no período de 1900 a 1924, por entendermos esse período como de grande importância na organização do trabalho livre na cidade. Assim, foram examinados cerca de 400 processos, levando-se em consideração os dados contidos na denúncia e os depoimentos do réu e das testemunhas. Desse conjunto de 400, foram selecionados 26 , por nos revelarem práticas culturais no tempo livre e de lazer dos trabalhadores urbanos e rurais, e que, de alguma forma, se tornaram cenário trágico com a ocorrência de um crime contra a vida.

Dessa maneira, foi possível perceber que apenas $6,5 \%$ do total dos processos analisados neste período foram abertos por crimes de homicídio cometidos nos momentos de lazer e divertimento.

Embora esse seja um percentual pequeno de ocorrências, entendemos que é de extrema importância a possibilidade de identificá-las, uma vez que são escassas as fontes de pesquisa que contribuem para uma história do lazer dos trabalhadores, devido à falta de registros documentais produzidos pelos mesmos ou que se remetam a eles.

A justificativa para a escolha da referida série foi pensar que, embora o crime cometido possuísse um grau de importância elevado, se deixássemos o crime cometido em um segundo plano poderíamos identificar a situação em que o mesmo ocorreu, deparando-nos com uma situação de tempo livre ou lazer que possibilitaria a identificação de uma parte do cotidiano das pessoas envolvidas.

Os dados coletados se remontam aos processos crime de homicídio que ocorriam devido a desentendimentos entre desafetos e conflitos. A investigação ocorrida nos processos crime 
possibilitou mostrar mais que os delitos. A leitura ampliada desses processos que foram selecionados permitiu identificar fragmentos dos movimentos urbanos e rurais dos conflitos ocorridos na cidade de Juiz de Fora e também os momentos de lazer e de divertimento dos trabalhadores nesses ambientes.

\section{Divertimentos dos trabalhadores em Juiz de Fora}

Para pensarmos nos divertimentos dos trabalhadores em Juiz de Fora, torna-se necessário pensarmos: o que seria o tempo livre? Numa tentativa de compreensão desse "tempo", dialogamos com Theodor Adorno (1995), em seu livro Palavras e sinais. Ao tentar conceituar a expressão tempo livre, o autor baseia-se na "diferença específica que o distingue do tempo não livre, que é preenchido pelo trabalho e, poderíamos acrescentar, na verdade, determinado desde fora" (ADORNO, 1995, p. 70). Além disso, Adorno afirma que o tempo livre dependerá da situação geral das sociedades. Por isso, ele pode se apresentar de diferentes formas, conforme a passagem dos tempos e de acordo com os hábitos de cada comunidade.

Em seu ensaio Tempo, disciplina de trabalho e capitalismo industrial, Edward P. Thompson (1998) diz que, no povo inglês do período pré-industrial, o tempo era marcado conforme os processos familiares, os modos de vida, os ciclos de trabalhos e da vida doméstica. Nota-se, então, que houve uma evolução na medição de intervalos de tempo, chegando ao ponto de que o relógio nas sociedades industriais se torna necessário para a contagem do tempo de trabalho. Com o desenvolvimento do capitalismo, da industrialização e dos modos de vida urbano, o tempo contabilizado pelo relógio permitiu uma organização mais racional, mecânica e rígida do trabalho e da existência humana, cujas dimensões da vida cotidiana passaram a ser divididas, contadas e regulamentadas.

Essa nova organização do tempo permitiu que a diferenciação dos tempos sociais ocorresse. O tempo sem trabalho passava a ser entendido mais como um tempo de repouso do que de lazer. 
Surgia, também, como um tempo voltado ao cumprimento ritual. Assim, a religião, as festas, o divertimento e a restauração das forças de trabalho continuavam profundamente relacionados. $O$ trabalho e o lazer permaneciam intimamente ligados e qualquer alteração de um afetaria diretamente o outro (CORBIN, 2001).

Dessa maneira, compartilhando das ideias de Thompson (1998) e Corbin (2001), bem como de Norbert Elias (1985), em seu ensaio $O$ lazer no espectro do tempo livre, compreendemos que todas as atividades de lazer são atividades de tempo livre, mas nem todas as atividades de tempo livre são atividades de lazer. Elias ainda (1985) destaca que:

[...] as características especiais das atividades de lazer só podem ser compreendidas se forem consideradas não apenas em relação ao trabalho profissional, mas, também, em relação às várias atividades de não lazer, no quadro de tempo livre. Desta maneira, o espectro do tempo livre contribui para dar maior precisão ao problema do lazer. (ELIAS, 1985, p. 54).

Portanto, o tempo livre está para além das atividades de lazer, englobando também as atividades de rotina, tais como os cuidados pessoais, o tempo para o cuidado com a casa e com os familiares e o tempo para o trabalho pessoal.

No entanto, aqui, privilegiaremos as práticas voltadas ao lazer nesse tempo livre, na tentativa de refletir sobre essas práticas que são concebidas em contraposição ao tempo de trabalho.

No dia onze de abril de 1903, um sábado de Aleluia, por volta das oito horas da manhã, o lavrador Geraldo Laurindo da Silva, de trinta e dois anos, morador do distrito do Rosário ${ }^{3}$, estava no arraial de São Francisco de Paula, que se encontrava em festa por comemoração da Semana Santa (AHJF, 1903). Participando de uma banca de jogo que acontecia nas imediações do botequim

3 Tanto o distrito do Rosário quanto o arraial de São Francisco de Paulo eram pertencentes a Juiz de Fora e compunham sua zona rural. (ESTEVES; LAGE, 1915). 
de Pascoal Petresi, Geraldo se divertia com o jogo jaburu 4 em companhia de aproximadamente trinta pessoas, entre as quais, "Martiniano de tal", que era o banqueiro desta mesa de jogos. Aconteceu que, de repente, um dos jogadores reclamou por certa quantia de dinheiro que ele alegava ter ganhado; não concordando com a alegação do jogador, Martiniano o esbofeteou. Geraldo e João Sabino reprovaram a reação agressiva de Martiniano e, por isso, viraram a mesa de jogo. Martiniano, enfurecido, perseguiu Geraldo e tentou agredi-lo com uma navalha, mas, não conseguindo, atirou-se em luta corporal com o mesmo. Numa atitude de tentar separar o conflito que ali se instalou, João Sabino, com um cacete, deu uma bordoada na cabeça de Martiniano. Nesse mesmo momento, ouviu-se um estampido de arma de fogo; era Cezarino Gomes de Oliveira, que puxara o gatilho de sua garrucha e atingira a Geraldo, que então caiu por terra abraçado em Martiniano. Geraldo veio a falecer cerca de trinta dias depois, pelo agravo dos ferimentos causados pelo tiro.

Durante esse processo crime, foram ouvidas nove testemunhas, muitas delas residentes no arraial de São Francisco de Paula e que estavam no festejo daquele dia. Todas as testemunhas apresentaram versões próximas da denúncia, no entanto nenhuma delas pronunciou que estava na mesa de jogo junto aos envolvidos no delito, apenas que estavam nas proximidades da jogatina ou que haviam ouvido falar sobre o acontecimento por parte de um "fulano de tal".

Quando analisamos os processos crime elegidos para este trabalho, percebemos que aproximadamente $30 \%$ deles são

4 Conforme relato da vítima Geraldo Laurindo da Silva, no momento em que a mesa foi virada, tanto o dinheiro quanto a roleta caíram no chão. O que permite inferir que este parecia ser um jogo de aposta em que se utilizava roleta para designar o ganhador. (AHJF, Série 24, cx 41, 11 abr. 1903, p. 08). Conforme o Dicionário online Michaelis, em um de seus significados, "jaburu" seria: "3. Espécie de roleta, com figuras de animais ao invés de números". DICIONÁRIO MICHAELIS. Disponível em: <http://michaelis.uol.com.br/ moderno/portugues/index.php?lingua=portugues-portugues\&palavra=jaburu> Acesso em: 20 maio 2015. 
relativos à temática "jogos", incluindo os jogos de azar e jogos esportivos, como é o caso do jogo de malha que aparece em uma ocorrência. Além do jogo chamado jaburu, também há a ocorrência do jogo chamado buzio ou busio e do jogo truc ou truco e douradinha.

Conforme Eloísa Oliveira e Vanderci Aguilera (2007) e ainda Ana Paula Puzzinato e Vanderci Aguilera (2006), ao estudarem a influência do africanismo na geolinguística e lexicografia brasileira, a palavra buzio ou busio varia de buzo, que deriva da lexicografia africana e significa jogo popular que utiliza cascas de laranja, pequenas conchas ou grãos de milho, ao invés de dados. Isso nos leva a crer que tal prática provavelmente foi inserida na região através da cultura dos escravos que trabalhavam nas fazendas e permaneceu como prática entre os populares.

Já o truco é um jogo de cartas que tem sua origem na Inglaterra no século XVII. Uma de suas variações é a douradinha, que se caracteriza quando há mais de seis jogadores. Conforme Tizuco Kishimoto (1994), o jogo se expande, pelos séculos seguintes, à Idade Média, associado ao dinheiro, à novidade, ao não sério, possibilitando que a atividade lúdica se desenvolvesse na vida social das comunidades à margem da religião oficial que abominava essas práticas. Segundo Kishimoto (1994), a Encyclopédie, de Diderot e D’Alembert, mostra que, no século XVII, o jogo aparece como uma ocupação fútil, divertimento, acaso, perda de fortuna e honra, sagacidade, uma espécie de convenção para se usar a habilidade, que diverte pela esperança do ganho (KISHIMOTO, 1994, p. 118).

A situação do jogo no Brasil durante a década de 1920 é bem representada por Nicolau Sevcenko (1992), que, em seu trabalho Orfeu extático na metrópole, indica a concepção do jogo na sociedade paulista durante aquele período. Para ele, o jogo poderia ser compreendido como fonte de excitação e possuía a característica de ser uma prática de mais fácil acesso, amplamente difundido nos vários setores da sociedade e por muitas vezes divulgado nos periódicos em tom dúbio, de forma acriminosa e também produzindo "efeitos de maneira horrível" (p. 86). Várias 
vezes o jogo adquiria característica de "virtude e como fato da vida desde que praticado com obstinada convicção e ilimitada ambição; fosse no mercado internacional, doméstico, no urbano, na política, na roleta ou no esporte." (SEVCENKO, 1992, p. 87).

Já alertava Walter Benjamin (1995) sobre o perigo inconsciente da paixão pelo jogo:

O jogo, como qualquer outra paixão, dá a conhecer seu rosto como a faísca que salta, no âmbito do corpo, de um centro a outro, mobilizando ora este, ora aquele órgão, e reunindo e confinando nele a existência inteira. [...] O jogo tem devotos apaixonados, que o amam por ele mesmo e de modo algum pelo que ele dá. E mesmo que o jogo lhes tire tudo, procuram a culpa em si mesmos. Dizem então: - Joguei mal. (BENJAMIN, 1995, p. 264-265).

Dos processos elegidos relativos à temática "jogos", apenas uma ocorrência foi constatada na área urbana da cidade, no bairro Pito Aceso, região hoje dos bairros Manoel Honório e Bonfim. Esta ocorrência pode ser classificada em duas temáticas de lazer, a dos jogos e a dos botequins existentes na cidade, e, devido a sua riqueza de detalhes, será analisada a seguir.

Ao localizarmos os delitos que ocorreram em botequins, cerca de $27 \%$ perfazem o total de processos de homicídio selecionados para essa análise. Vejamos a ocorrência comentada acima através do relato das testemunhas.

$\mathrm{Na}$ noite de sábado do dia dezessete de novembro de 1923, Veríssimo Venâncio da Silva, um operário de trinta e dois anos de idade, morador no bairro Manoel Honório, vizinho do botequim de Anacleto Eugênio Vidal, encontrava-se dentro deste comércio com amigos que jogavam truco e douradinha como forma de passar o tempo, quando, por volta de dez e meia da noite, apareceu no botequim Francisco de Paula, um soldado do $10^{\circ}$ Regimento de Infantaria. Ao interromper o jogo, o soldado Francisco, acompanhado de um colega do regimento, dirigiu-se de forma agressiva aos amigos que se divertiam, soltando um "para com essa merda, ahi". Sua intenção era que se parasse 
com o jogo para iniciar um outro, o jogo de víspora. Veríssimo, percebendo que tal situação poderia terminar mal, uma vez que o soldado tinha fama de valentão e desordeiro, se retirou para sua casa, quando, de repente, ouviu o som de um estampido. Não querendo voltar para o botequim com receio de que alguma confusão tivesse ocorrido, somente no dia seguinte ele passou a saber que Anacleto havia atirado em Francisco, assassinando-o (AHJF, 1923).

A testemunha Augusto Estopa, um verdureiro de sessenta e seis anos, também morador do Manoel Honório e que participava do jogo no botequim, ainda revelou à polícia que Anacleto, o dono do botequim, disse ao soldado Francisco que, além de não haver víspora em seu estabelecimento, ele não consentia jogo em sua casa, e apenas estavam amigos jogando uma partida de douradinha, mas sem apostas em dinheiro. Mesmo assim Francisco intimou a Anacleto que parasse o jogo, quando seu colega soldado tentou retirá-lo do botequim. No entanto, Francisco, possuindo um bastão de pau nas mãos, quebrou o lampião do botequim e deu outra bordoada em Anacleto, que não se machucou, pois entrou para o interior da casa onde morava, e de onde voltou armado. Francisco chegou a ser contido por quatro homens, mas conseguiu se soltar e desfechar nova bordoada em Anacleto, que Ihe acertou com um tiro. Francisco faleceu momentos depois.

Outro relato interessante nesse mesmo processo é o do colega de Francisco, João Paulo da Silva, que era praça do $10^{\circ}$ Regimento de Infantaria e indicou que eles retornavam de um baile que havia ocorrido na região do Pito Acesso. Ao entrarem no botequim para comprar um maço de cigarros, João Paulo recomendou a Francisco que não bebesse mais, pois ele já havia bebido e a rua estava escorregadia devido à chuva que havia caído. A partir daí ocorreu o que as outras testemunhas já haviam narrado.

Alguns elementos podem ser analisados nesse processo crime. O primeiro deles é a forma agressiva com que o soldado interrompe o divertimento, faz o dono do botequim tomar 
providencias para colocar ordem na situação, chegando ao extremo de utilizar arma de fogo na questão. Se, de certo modo, o dono do botequim agiu para manter a honra em seu estabelecimento comercial como forma valorativa de manter seu lugar no mundo social, ao mesmo tempo, podemos perceber o uso indiscriminado da arma de fogo.

Uma questão que nos chamou atenção foi a presença apenas de homens nesse processo de 1923 e no processo citado anteriormente, de 1903. Neles, tanto os réus quanto as vítimas e testemunhas envolvidas são homens, o que nos permite pressupor que tanto os locais em que ocorriam os jogos, quanto os botequins e tavernas, eram locais predominantemente frequentados por homens, mesmo no momento de compras dos gêneros de primeiras necessidades nas vendas e nos botequins. Os espaços dos botequins e das vendas funcionariam como espaços de trocas de experiências sociais e econômicas, possibilitando também a sociabilidade masculina.

Em sua maioria, os desentendimentos aconteciam nesses locais devido à intolerância de gestos ou falas agressivas e grosseiros entre os frequentadores, ou mesmo de acertos de conta que pretendiam humilhar a honra da vítima.

Outro elemento comum nos botequins, nas vendas e nos restaurantes era a bebida. Quer fosse a cerveja produzida nas inúmeras fábricas que existiam na cidade ou a cachaça, elas eram constantemente atribuídas ao réu ou à vítima dos delitos. Inúmeras vezes, as testemunhas qualificavam o réu como possuindo o hábito de embriagar-se, enquanto forma de desqualificação de sua honra e seu caráter. No entanto, cabe destacar que a bebida também era utilizada para interação social dentro dessas casas comerciais, permitindo que houvesse vínculos sociais entre os frequentadores desses locais (CARNEIRO, 2008).

Já em uma noite de julho no ano de 1917, na Fazenda Santa Clara, distrito de Vargem Grande (atual cidade de Belmiro Braga), pertencente à cidade de Juiz de Fora, Benedito Glória, com cinquenta anos de idade, nascido na Bahia, estava com outros camaradas, festejando com danças o término da colheita 
do café no terreiro desta fazenda, onde também residia. Em certo momento da noite, ouviu-se um tiro que partiu de um rancho ali próximo e feriu a Pedro Domingos e sua filhinha, Julia Carolina de Jesus, vindo a falecer Pedro. De acordo com os relatos das testemunhas, embora Paulino Marciano Januário da Silva tenha atirado em Pedro, não havia inimizade entre eles, e o ocorrido pareceu ter sido um acidente (AHJF, 1917).

Através desse relato, podemos identificar uma situação festiva em ambiente rural que exemplifica uma conjuntura recorrente na vida campesina, pois, nos processos elegidos para esta pesquisa, apenas uma ocorrência é de um baile em ambiente urbano.

O processo acima descrito nos permite identificar uma organização e uma sistematização na vida rural, desde a plantação até a colheita. Nesse sentido, a festa é um ato coletivo que implica uma determinada organização em sua produção. Preparada, planejada e montada em conjunto entre o dono das terras e seus colonos, ela permitia o estabelecimento de sociabilidades na vida cotidiana dos envolvidos. Nesse ambiente, ela permitia um afastamento das atividades cotidianas e a produção de uma identidade.

\section{Algumas considerações}

A utilização dos processos judiciais como fontes de pesquisa indica uma importante possibilidade, amplitude e diversidade de temáticas e informações a serem pesquisadas.

Podemos perceber, entre os exemplos aqui mencionados, que, por deslizes, intolerância e mesmo questões de honra e respeito, os crimes eram cometidos em momentos de lazer e de tempo livre dos trabalhadores. Muitas das vezes, os momentos de lazer eram esperados pelos criminosos para realizar o crime, principalmente quando havia inimizade entre os envolvidos.

Importante atentar também para a influência de práticas afrodescendentes, como é o caso do jogo búzio, relatado em vários 
processos quando havia a questão do jogo no envolvimento do ato criminoso. É possível que, nos primeiros anos do Novecentos, a prática desse jogo e de outros com influência africana fosse presente nessa localidade, pois a presença de escravos e libertos se fazia visível mesmo após a abolição. No entanto, deve-se chamar atenção para o fato de que as práticas possam ter sofrido modificações com o passar dos anos, permitindo, contudo, que as raízes da cultura africana permanecessem, o que nos faz refletir sobre a influência de uma cultura sobre outra e sobre a apropriação das práticas. O mesmo deve ser pensado em relação ao imigrante europeu que também se instalou na região.

Diferentemente do que se pode inferir sobre uma possível concentração de possibilidades de divertimento na região urbana da cidade, também é significante a identificação da experiência de atividades de lazer no mundo rural, fato que pode ser observado nos distritos da cidade relatados nos processos. Dessa maneira, através dos processos crime, é possível identificar alguns costumes na região rural da cidade, localidade aquela em que esses costumes muitas vezes são difíceis de serem estudados por escassez de registros dos acontecimentos, situação diferente dos centros urbanos, que possuem uma maior quantidade de fontes de pesquisa a serem utilizadas.

Mesmo que a causa dos processos jurídicos tivesse um grau de importância devido ao fato de se tratar de um crime de consequências máximas, através dos relatos desses crimes também é possível notar a ocorrência de momentos de sociabilidades entre os envolvidos, revelando que a população se permitia experimentar os divertimentos nos tempos livres do trabalho, ainda que estes divertimentos tivessem alguma aproximação com o trabalho, como é o caso dos festejos relacionados à colheita. 


\section{Fontes de pesquisa}

ARQUIVO HISTÓRICO DE JUIZ DE FORA - AHJF, Fundo Fórum Benjamin Colucci.

Processos crime de homicídio, Série 24, Caixa 41, 11 abr. 1903.

Processos crime de homicídio, Série 24, Caixa 58, 27 jul. 1917.

Processos crime de homicídio, Série 24, Caixa 58, 18 nov. 1923.

CÂMARA MUNICIPAL DE JUIZ DE FORA. Resolução no 706. In: Resoluções da Câmara Municipal de Juiz de Fora: Annos de 1915 e 1916. Juiz de Fora: Typografia Noronha, 1917.

ALMANACH DE JUIZ DE FORA PARA 1917. Juiz de Fora: Typographia Gutemberg - J. Ribeiros \& Comp., 1917.

\section{JORNAIS}

O PHAROL, Juiz de Fora, 17 out. 1907.

O PHAROL, Juiz de Fora, 11 set. 1909.

ESTEVES, A.; LAGE, O. V. B. Álbum do município de Juiz de Fora. Belo Horizonte: Imprensa Oficial de Minas Gerais, 1915.

\section{Referências bibliográficas}

ADORNO, Theodor W. Tempo livre. In: ADORNO, Theodor W. Palavras e sinais: modelos críticos 2. Trad. Maria Helena Ruschel. Petrópolis: Vozes, 1995.

BENJAMIN, Walter. Rua de mão única. 5. ed. São Paulo: Brasiliense, 1995. Obras escolhidas v. II. 
CARNEIRO, Deivy Ferreira. Conflitos verbais em uma cidade em transformação: justiça, cotidiano e os usos sociais da linguagem em Juiz de Fora (1854-1941). Tese (Doutorado em História) - Programa de Pós-Graduação em História, Universidade Federal do Rio de Janeiro, Rio de Janeiro, 2008.

CHALHOUB, Sidney. Trabalho, lar e botequim. Campinas: Unicamp, 2001.

Cidade febril: cortiços e epidemias na corte imperial. São Paulo: Companhia das Letras, 1996.

CHRISTO, Maraliz Castro Vieira. Europa dos pobres: a belle-époque mineira. Juiz de Fora: EDUFJF, 1994.

CORBIN, Alain. História dos tempos livres. Lisboa: Teorema, 2001.

DICIONÁRIO MICHAELIS. Disponível em: <http://michaelis.uol. com.br/moderno/portugues/index.php?lingua=portuguesportugues\&palavra=jaburu> Acesso em: 20 maio 2015.

ELIAS, Norbert. O espectro do tempo livre. In: DUNNING, E; ELIAS, N. (Orgs). A busca da excitação. Lisboa: DIFEL, 1985.

GIROLETTI, Domingos. Industrialização de Juiz de Fora. Juiz de Fora: EDUFJF, 1988.

HOBSBAWM, Eric J. Mundos do trabalho. Novos estudos sobre história operária. Rio de Janeiro: Paz e Terra, 1987.

KISHIMOTO, Tizuco Morchida. O jogo e a educação infantil. Perspectiva. Florianópolis, v. 12, n. 22, p. 105-128, 1994.

OLIVEIRA. P. História de Juiz de Fora. 2 ed. Juiz de Fora: Gráfica Comércio e Indústria, 1966.

OLIVEIRA, Eloisa Elena; AGUILERA, Vanderci de Andrade. Africanismo, geolingüística e lexicografia: um estudo de convergências e divergências. Revista Afroatitudeanas, v. 2, 2007. Disponível em: <http://www.uel.br/ revistas/afroatitudeanas/volume-2-2007/Eloisa\%20Elena.pdf > Acesso em: 5 abr. 2015. 
PUZZINATO, Ana Paula e AGUILERA, Vanderci de Andrade. A presença de africanismos na língua portuguesa do Brasil. In. Revista Afroatitudeanas, vol.1, 2006. Disponível em: <http://www.uel.br/revistas/ afroatitudeanas/volume-1-2006/Ana\%20Paula\%20Puzzinato.pdf> Acesso em: 5 abr. 2015.

SEVCENKO, Nicolau. Orfeu extático na metrópole: São Paulo, sociedade e cultura nos frementes anos 20. São Paulo: Companhia das Letras, 1992.

. Literatura como missão: tensões sociais e criação cultural na Primeira República. São Paulo: Brasiliense, 1999.

. A capital irradiante: técnica, ritmos e ritos do Rio. In: SEVCENKO, Nicolau. (Org.). História da vida privada no Brasil. São Paulo: Companhia das Letras, 1998. v. 3.

THOMPSON, Edward Palmer. Tempo, disciplina de trabalho e capitalismo industrial. In: . Costumes em comum. São Paulo: Companhia das Letras, 1998.

VAGO, Tarcisio Mauro. Cultura escolar, cultivo de corpos: educação physica e gymnastica como práticas constitutivas dos corpos de crianças no ensino público primário de Belo Horizonte (1906-1920). Bragança Paulista: EDUSF, 2002.

VEIGA, Cynthia Greive. Cidadania e educação na trama da cidade: a construção de Belo Horizonte em fins do século XIX. Bragança Paulista: EDUSF, 2002.

Recebido em agosto de 2016.

Aprovado em maio de 2017. 